\title{
PROCESSO DE TRABALHO NO SAMU E HUMANIZAÇÃO DO SUS DO PONTO DE VISTA DA ATIVIDADE HUMANA
}

\author{
THE SAMU WORK PROCESS AND THE HUMANIZATION DEVELOPED BY THE UNIQUE HEALTH \\ SYSTEM FROM THE STANDPOINT OF HUMAN ACTIVITY
}

\author{
Ana Rita Castro Trajano ${ }^{1}$ \\ Daisy Moreira da Cunha ${ }^{2}$
}

Resumo Procura-se analisar o trabalho dos profissionais do Serviço de Atendimento Móvel de Urgência (Samu) e a Política Nacional de Humanização do Sistema Único de Saúde (PNH/SUS) do ponto de vista da atividade humana. Pergunta-se sobre as possibilidades de 'humanização do processo de trabalho' no Samu e sobre o 'agir competente' da urgência móvel em saúde, a partir de referenciais ergológicos. Para construção do artigo partiu-se de discussões marxistas sobre o processo de trabalho como produção de valores de uso; em seguida, abriu-se diálogo sobre processo de trabalho em saúde com base em autores do campo da saúde coletiva e da PNH. A perspectiva ergológica do trabalho é aprofundada no item seguinte, de modo a contribuir para uma análise da atividade dos trabalhadores do Samu/Belo Horizonte durante o atendimento a uma ocorrência de acidente. Palavras-chave ergologia; atividade humana; processo de trabalho; urgência móvel; humanização.
Abstract It is aimed to analyse the work of the professionals from Samu (Service of Mobile Emergency) and the Nacional Humanization Politics (PNH) developed by the Unique Health System (SUS) from the standpoint of human activity. Wondering about the possibilities of 'humanizing the Samu work process' and about the 'act in competence' in the mobile health emergency since the ergologic regardings. The article has as primary basis marxist references on debating about the work process as production of values of use; forththwith, a dialogue about the work process regarding health care since the authors of Public Heath and PNH field. The ergologic perspective about labor is further discussed on the next item, in such a way that contributes to the analisis of Samu/Belo Horizonte workers activities, during the attendance for an accident occurrence.

Keywords ergology; human activity; work process; mobile health urgency; humanization. 
O artigo discute o trabalho no Serviço de Atendimento Móvel de Urgência (Samu) do Sistema Único de Saúde (SUS), problematizando questões levantadas pela pesquisa de doutorado em andamento, intitulada "O trabalho dos profissionais do Samu e a Política Nacional de Humanização do ponto de vista da atividade: saberes, valores e competências", 3 que é parte integrante da linha de pesquisa Política, Trabalho e Formação Humana, do Programa de Pós-Graduação em Educação da Universidade Federal de Minas Gerais (UFMG).

Num primeiro momento, retomam-se referenciais marxistas na discussão sobre o processo de trabalho como produção de valores de uso. Em seguida, abre-se diálogo sobre processo de trabalho em saúde com base em autores do campo da saúde coletiva e da Política Nacional de Humanização (PNH) do SUS. A perspectiva da abordagem ergológica do trabalho aparece entre tais autores, sendo aprofundada no item seguinte, de modo a contribuir para uma análise da atividade dos trabalhadores do Samu de Belo Horizonte $(\mathrm{BH})$ durante o atendimento a uma ocorrência de acidente.

Ao buscar desvelar o ponto de vista da atividade numa perspectiva ergológica, esperamos contribuir para as discussões sobre processo de trabalho em saúde e para a humanização do SUS.

\section{O processo de trabalho como produção de valores de uso}

Ao abordar o trabalho como "um processo de que participam o homem e a natureza", Marx ressalta o movimento de todo o corpo na relação do homem com a natureza, ou em suas palavras: "[O trabalho] Põe em movimento as forças naturais de seu corpo, braços e pernas, cabeça e mãos, a fim de apropriar-se dos recursos da natureza, imprimindo-lhes forma útil à vida humana" (Marx, 1987, p. 202).

Chama-nos a atenção esta abordagem do trabalho como movimento que envolve todo o corpo, na relação entre o ser humano e a natureza externa, em que, ao atuar sobre a mesma, simultaneamente modifica-a - o ser que trabalha modifica sua própria natureza. Nesse processo, afirma Marx (1987, p. 202), “desenvolve potencialidades nela adormecidas e submete ao seu domínio o jogo das forças naturais".

Outra questão apontada por Marx e que serve de base aos estudos sobre o trabalho é a capacidade, exclusivamente humana, de projetar o próprio trabalho, antes de realizá-lo. É bem conhecida a abordagem marxiana que diferencia "o pior arquiteto da melhor abelha". Nas palavras do autor: "o que distingue o pior arquiteto da melhor abelha é que ele figura na mente sua construção antes de transformá-la em realidade". A partir daí, afirma que "no fim do processo de trabalho aparece um resultado que já existia antes idealmente na imaginação do trabalhador" (Marx, 1987, p. 202). 
Retomemos os elementos que compõem o processo de trabalho, segundo Marx (1987): 1) a atividade adequada a um fim, isto é, o próprio trabalho; 2) a matéria a que se aplica o trabalho, o objeto de trabalho; 3) os meios de trabalho, o instrumental de trabalho.

Importante destacar que são os meios/instrumentos com que se faz o trabalho - e não o que se faz - que distinguem as diferentes épocas econômicas. Em síntese: “Os meios de trabalho servem para medir o desenvolvimento da força humana de trabalho e indicam as condições sociais em que se realiza o trabalho" (Marx, 1987, p. 204).

Como "meios de trabalho" entende-se, além do arsenal tecnológico/maquinarias utilizadas para transformar o "objeto de trabalho", todas as condições materiais em que se realiza o trabalho, desde a terra, como meio universal de trabalho, até aquelas que são resultado do trabalho anterior, como edifícios, estradas, mobiliário, dentre outras.

A noção de atividade já estava presente nesses estudos sobre processo de trabalho, em que aparece subordinada a um objetivo ou fim. Nas palavras de Marx (1987, p. 205): “No processo de trabalho, a atividade do homem opera uma transformação, subordinada a determinado fim, no objeto sobre que atua por meio do instrumental de trabalho. O processo extingue-se ao concluir-se o produto".

Nesta perspectiva, o trabalho é atividade com vista a um fim, ou uma atividade orientada por um objetivo. Importante ressaltar que este objetivo diz respeito tanto ao projeto de quem trabalha, como daquele a quem se subordina o trabalhador. Numa linguagem ergológica, diríamos que, no curso da atividade, o trabalhador faz uso de si 'por si' e uso de si 'pelo outro'. Abordaremos esta temática em item específico sobre a mesma, adiantamos o que nos diz Yves Schwartz ao discutir sobre a ambiguidade do conceito de atividade, quando procura historiar o conceito e discute as elaborações de Marx. Em suas palavras:

Impossível escapar à sofisticação do 'objetivo' que pode ser, em graus diversos, e diversamente congruentes ou contraditórios, o do trabalhador - na medida em que é único e claro para ele mesmo - e o das diversas entidades sociais no seio das quais esse processo de trabalho se desdobra. A simples menção do 'objetivo' obriga, portanto, a sair da definição neutra e a-histórica para imergir a Tätigkeit em figuras históricas concretas (Schwartz, 2004a, p. 40-41).

Do ponto de vista do produto/resultado, o meio e o objeto de trabalho são considerados meios de produção. Introduz-se aqui a noção de 'valor de uso', o produto como valor de uso, e o processo de trabalho como atividade dirigida com o fim de criar valores de uso, que podem se tornar meios de produção de outros processos de trabalho. Neste sentido, o objeto de trabalho 
é 'matéria-prima', ou seja, “um objeto já filtrado pelo trabalho, um produto do próprio trabalho" (Marx, 1987, p. 206). E ainda, um mesmo produto, dependendo de seu lugar no processo de trabalho, pode funcionar como meio de trabalho ou matéria prima.

Quando os produtos servem de meios de produção, em novos processos de trabalho, perdem o caráter de produto e, nessa função, aparecem como 'fatores materiais' do processo de trabalho, seja como meios ou objeto de trabalho. Neste caminho, Marx vai falar sobre a máquina considerada como trabalho morto, que ganhará vida, se assim podemos dizer, através do trabalho humano, ou, como diz o autor, pelo "seu contato com o trabalho vivo". Vale aqui deixar que ele fale por nós:

Uma máquina que não serve ao processo de trabalho é inútil. (...). O fio que não se emprega na produção de tecido ou de malha é algodão que se perde. O trabalho vivo tem de apoderar-se dessas coisas, de arrancá-las de sua inércia, de transformá-las de valores de uso possíveis em valores de uso reais e efetivos (Marx, 1987, p. 207-208).

Importante destacar que, na perspectiva marxiana, o processo de trabalho, que é descrito em seus "elementos simples e abstratos" como "atividade dirigida com o fim de criar valores de uso, de apropriar os elementos naturais às necessidades humanas" (Marx, 1987, p. 208), não depende das condições sociais em que é realizado. Nesse sentido, o "processo de trabalho (...) é condição natural eterna da vida humana, sem depender, portanto, de qualquer forma dessa vida, sendo antes comum a todas as suas formas sociais" (Marx, 1987, p. 208). Aqui não se trata das relações entre os trabalhadores, como também entre eles e o capitalista - proprietário dos meios de produção, aquele que compra a força de trabalho como 'mercadoria'. Não entraremos, neste momento, na abordagem do modo de produção capitalista ou de outro qualquer; enfatiza-se a natureza geral do processo de trabalho de produzir valores de uso, ou seja, coisas que sirvam para satisfazer necessidades humanas/sociais. Neste caso o processo de trabalho é considerado à parte de qualquer forma ou estrutura social: “A produção de valores de uso não muda sua natureza geral por ser levada a cabo em benefício do capitalista ou estar sob o seu controle" (Marx, 1987, p. 202).

A compreensão desta abordagem geral do processo de trabalho como 'produção de valores de uso' contribui para discussões sobre o trabalho em saúde, em especial, no campo da saúde pública, temática que desenvolveremos em tópico posterior.

Ressalta-se que, a partir desta abordagem da natureza geral do processo de trabalho, Marx introduzirá análise sobre o processo de produzir mais valia, que, poderíamos dizer, é particular do modo de produção capitalista, ou seja, 
da forma social em que "o trabalhador trabalha sob o controle do capitalista, a quem pertence seu trabalho" (Marx, 1987, p. 209). Conforme suas palavras:

Ao penetrar o trabalhador na oficina do capitalista, pertence a este o valor de uso de sua força de trabalho, sua utilização, o trabalho. O capitalista compra a força de trabalho e incorpora o trabalho, fermento vivo, aos elementos mortos constitutivos do produto, os quais também lhe pertencem (Marx, 1987, p. 210).

Em outras palavras, o capitalista compra a força de trabalho do trabalhador, e este ao trabalhar coloca esta força, que foi vendida como mercadoria, em ação.

A partir daí, podemos introduzir o conceito de valor de troca, ou simplesmente 'valor'; e o conceito de 'mais valia'. Consideremos o que diz Marx:

Na produção de mercadorias, nosso capitalista não é movido por puro amor aos valores de uso. Produz valores de uso apenas por serem e enquanto forem substrato material, detentores de valor de troca. (...). Além de um valor de uso quer produzir mercadoria, além de valor de uso, valor, e não só valor, mas também valor excedente (mais valia) (Marx, 1987, p. 210-211).

Poderíamos dizer, seguindo o pensamento marxiano, que, na sociedade “predominantemente movida pela lógica do capital, pelo sistema produtor de mercadorias" (Antunes, 1997, p. 77), o capitalista "quer produzir um valor de uso que tenha um valor de troca, um artigo destinado à venda, uma mercadoria" (Marx, 1987, p. 211), e que esta tenha um "valor mais elevado que o valor conjunto das mercadorias necessárias para produzi-la, isto é, a soma dos valores dos meios de produção e força de trabalho" (Marx, 1987, p. 211).

Vale ressaltar que, do ponto de vista do processo de trabalho, distinguem-se os elementos objetivos e subjetivos - os 'meios de produção' e a 'força de trabalho em atividade', respectivamente. Observa-se na abordagem marxiana do trabalho a noção de atividade - o que põe em movimento o corpo. Ao introduzir a temática do processo de trabalho, Marx (1987, p. 201) nos diz que "a utilização da força de trabalho é o próprio trabalho"; que o trabalhador, "ao trabalhar, torna-se realmente no que antes era apenas potencialmente: força de trabalho em ação, trabalhador".

Importante também destacar o aspecto quantitativo e o qualitativo, ao comparar o processo de trabalho com o processo de produzir valor. $\mathrm{O}$ processo de trabalho consiste no trabalho útil que produz valores de uso (considerado como trabalho concreto) e, nesta abordagem, 'a atividade é considerada em seu aspecto qualitativo', segundo seu objetivo e conteúdo. Em relação à produção de valor (dimensão abstrata do trabalho, como dispêndio de força humana de trabalho, no sentido fisiológico), segundo Marx (1987, 
p. 220), “o mesmo processo de trabalho é considerado apenas sob o aspecto quantitativo" - o tempo gasto pelo trabalhador para "executar a operação"; mercadorias que entram no processo de trabalho, consideradas "quantidades determinadas de trabalho materializado" etc.

Podemos concluir esta primeira abordagem marxiana do processo de trabalho e a diferença estabelecida, através da análise da mercadoria, entre 'trabalho concreto' e 'trabalho abstrato', com as considerações referentes ao que é particular do processo capitalista de produção. Segundo Marx:

O processo de produção, quando unidade do processo de trabalho e do processo de produzir valor, é processo de produção de mercadorias; quando unidade do processo de trabalho e do processo de produzir mais valia, é processo capitalista de produção, forma capitalista da produção de mercadorias (Marx, 1987, p. 222).

Passamos em seguida a discutir o processo de trabalho em saúde e a articulá-lo com a noção ergológica de atividade.

\section{Do debate sobre processo de trabalho em saúde}

Uma marca comum, se assim poderíamos dizer entre as discussões sobre processo de trabalho em saúde, no campo da saúde coletiva (e aqui incluímos a $\mathrm{PNH}$ ), refere-se à postura crítica diante dos Princípios de administração científica, de Frederik W. Taylor (1990). Nessa perspectiva, destacamse as formulações de Campos $(2005,2007)$, ao comentar sobre a atualidade dos princípios tayloristas: "Ainda que o campo da gestão se tenha ampliado desde 1911, a disciplina e o controle continuam sendo o eixo central dos métodos de gestão. A este eixo conformador do taylorismo denominou-se racionalidade gerencial hegemônica" (Campos, 2005, p. 23).

Em síntese, poderíamos dizer, que o método proposto por Taylor produz a fragmentação do trabalho e a expropriação do saber dos trabalhadores, através da parcelarização das tarefas e de uma visão de gestão como uma instância isolada, responsável pelas funções de preparação ou planejamento. (Campos, 2005, 2007; Tenório, 2005; Pasche, 2006; Santos-Filho e Barros, 2007).

Neste campo de análises emerge a temática da subjetividade e do sujeito na abordagem de processos de trabalho, assim como discussões que reconhecem a importância da reorganização destes para a mudança do modelo assistencial.

Campos propõe "repensar o significado e o modo como se organiza o trabalho", quando discute a hipótese referente à dupla finalidade do mesmo: "produzir bens e serviços necessários ao público, mas também cuidar da constituição do Sujeito e dos Coletivos". A partir daí, afirma que o trabalho está também "implicado com a própria constituição das pessoas e de sua 
rede de relações: equipes, grupos, organizações, instituições e sociedades" (Campos, 2005, p. 14).

Ressalta-se, no campo da urgência/emergência, o trabalho de Suely Deslandes (2002), que propõe uma análise do processo de trabalho, em suas palavras, "pelo viés das representações de seus agentes. Trabalhamos, portanto, com as percepções e representações que os trabalhadores da emergência constroem a partir de seu próprio processo de trabalho" (Deslandes, 2002, p. 45). A autora amplia, assim, a análise do processo de trabalho em saúde (PTS), ao propor incluir o ponto de vista dos trabalhadores através de suas representações/interpretações sobre a realidade do trabalho da urgência. Estas discussões trazem contribuições importantes para o debate sobre a valorização dos saberes 'da experiência', em especial aqueles criados no enfrentamento cotidiano de situações de violências que atravessam (e afetam) o PTS em serviços de urgência/emergência.

Numa abordagem singular sobre a relação dor-desprazer-trabalho, Regina Benevides de Barros e Maria Elizabeth Barros de Barros (2007), a partir de constatações sobre a atual precarização das relações de trabalho, destacam, no caso da saúde, "um outro vetor-dobra da gestão que se abre. É a dobra4 das políticas de saúde". Ainda segundo as autoras: "Não é possível propor/pensar a gestão em saúde, seja a gestão do sistema, seja dos serviços, seja a gestão da atividade, sem que se leve em conta o modo como estas políticas se constroem e o que nelas se reafirma como 'público'"'(Benevides de Barros e Barros de Barros, p. 65). Neste sentido, acentuam a complexidade da discussão sobre gestão em saúde, ao proporem uma análise ampla do processo de trabalho em que se incluem, além dos sujeitos e saberes, o poder (modos de estabelecer as relações) e as políticas públicas (coletivização destas relações). Eis a tese proposta por Benevides de Barros e Barros de Barros (2007, p. 62): “gestão não é apenas organização do processo de trabalho, mas é o que se passa entre os vetores-dobras que o constituem".

Neste diálogo em que se ampliam abordagens do PTS, encontramos autores que problematizam sobre a lógica hegemônica nesses processos, perguntando-se sobre a finalidade dos mesmos: produzir procedimentos ou produzir cuidados? Franco e Merhy (2006) partem de análises em que se reconhece a hegemonia do saber médico e da lógica da produção de procedimentos, ao discutirem e classificarem as tecnologias do trabalho em saúde, quando problematizam o PTS no debate sobre o atual modelo assistencial. “Tecnologias aqui entendidas como conjunto de conhecimentos e agires aplicados à produção de algo" (Franco e Merhy, 2006, p. 116). De acordo com os autores:

Este conhecimento pode estar materializado em máquinas e instrumentos, ou em recursos teóricos e técnicas estruturadas, como tecnologias duras e leve-duras, 
respectivamente, lugares próprios do 'trabalho morto'. Por outro lado, este conhecimento pode estar disperso nas experiências e modos singulares de cada profissional de saúde operar seu trabalho vivo em ato, como na produção de relações, tão fundamentais para o trabalho em saúde (...). Esta função criativa e criadora que pode caracterizar os serviços de saúde, a partir das relações singulares, é operada por 'tecnologias leves', território onde se inscreve o 'trabalho vivo em ato'. Buscar, na arena da produção de serviços de saúde, os lugares onde se matriciam o conhecimento e a forma de potencializá-los para a assistência à saúde é fundamental (Franco e Merhy, 2006, p. 116-117).

Nessa direção, os autores analisam o Programa de Saúde da Família (PSF), formulado pelo Ministério da Saúde em 1994 e considerado como uma resposta às críticas ao modelo médico-hospitalocêntrico, centrado numa visão biologicista do processo saúde-doença, em que predominam práticas curativas e medicamentosas. Não entraremos aqui na análise do PSF, interessanos extrair elementos que contribuam para a discussão dos PTS. Para isso, destacamos o que nos dizem Franco e Merhy (2006) sobre a impossibilidade de se promover mudanças na organização do trabalho médico-cêntrico apenas com a constituição de equipes multiprofissionais como núcleo da produção da assistência. É necessário mais do que isto, trata-se de produzir mudanças dos sujeitos envolvidos com o trabalho, o que significa que é preciso associar, às novas configurações tecnológicas, a construção de nova ética que o oriente, ancorada em novos valores, como "solidariedade, cidadania e humanização da assistência" (Franco e Merhy, 2006, p. 116).

Estas abordagens críticas sobre a hegemonia dos saberes/fazeres médicos e da lógica da produção de procedimentos em contraposição à lógica da produção de cuidado despertam nossa atenção para o debate em que se contrapõem valores do bem comum ou do interesse público versus valores mercantis ou de mercado (Schwartz, 1996, 2002). Em seguida, discutiremos referenciais sobre o trabalho em saúde propostos por autores vinculados à $\mathrm{PNH}$ do SUS, através dos quais se desvela como estes debates se materializam nas dimensões do processo de trabalho.

Importante destacar que a PNH é formulada a partir da compreensão de que os modos de atenção e de gestão são indissociáveis, inseparáveis. Em outras palavras, não há como mudar práticas de atenção sem alterar a gestão dos processos de trabalho. Articula-se a este primeiro princípio a aposta na autonomia, no protagonismo e na corresponsabilidade dos sujeitos implicados com a produção de saúde (Brasil, 2008).

Heckert, Passos e Barros (2009) contribuem com reflexões sobre gestão dos PTS, quando dialogam com a noção ergológica do 'debate de valores' (Schwartz, 1996, 2002) que atravessa toda atividade de trabalho. 
Entende-se que a gestão dos processos de trabalho em saúde não pode ser reduzida à sua dimensão gerencial-administrativa separada das práticas de cuidado, ou seja, não pode se identificar com uma lógica gerencial marcada pelos valores de mercado (Heckert, Passos e Barros, 2009, p. 494).

Em seguida, os autores discutem a relação entre cuidar e gerir, problematizando os processos de trabalho em que predominam 'práticas hierarquizantes e de dominação' e concluem com a proposta de outra abordagem: "enfatizar as dimensões dos processos de trabalho que afirmam valores do bem comum" (Heckert, Passos e Barros, 2009, p. 494).

O trabalho em saúde é concebido como atividade que se realiza não como uma instância separada da gestão da própria atividade. Nesse sentido, toma-se a gestão não como algo separado do cuidado, como uma instância administrativo-gerencial, responsável pelas prescrições, decisões e organização do trabalho, mas como processo que se realiza e se atualiza pelos sujeitos em atividade. No prosseguimento das discussões, Benevides de Barros e Barros de Barros chamam atenção para as características muito especiais do produto de um PTS, tomado não como mercadoria a ser colocada à venda no mercado de bens de consumo capitalista, mas como um serviço em defesa da vida e da saúde das pessoas: "Pensar a gestão em saúde é pensar modos de produção comprometidos com a vida" (Benevides de Barros e Barros de Barros, 2007, p. 65).

Ao definir trabalho como atividade e enfatizar a 'dimensão gestionária' do mesmo, outros autores também trazem referenciais ergológicos para aprofundar formulações da PNH sobre as relações entre trabalho e gestão. Schwartz (2004b), problematizando a "deriva trabalhar, gerir", ao discutir o trabalho como "uso dramático de si", recusa a tese de que há gestão apenas por especialistas habilitados como tais. Nesta perspectiva trabalhar é gerir.

Dentre os autores que contribuem para a discussão sobre a PNH, destaca-se Hennington (2007, p. 12) ao ressaltar "a gestão dos processos de trabalho como parte vital da política de humanização em saúde", o que marca a diferença do sentido atribuído pela $\mathrm{PNH}$ à humanização em saúde em relação à concepção "restrita e focada na relação trabalhador-usuário e no cumprimento de preceitos éticos" (Hennington, 2007, p. 4). A autora nos mostra que, para além das questões macrossociais, políticas e econômicas, a $\mathrm{PNH}$, ao formular como um dos seus princípios a inseparabilidade entre atenção e gestão do processo de trabalho, reconhece o trabalhador da saúde como protagonista e corresponsável pela gestão do trabalho. Conclui, então, que a 'inclusão do trabalhador', reconhecendo-se saberes e valores construídos na experiência, em articulação com os saberes protocolares, possibilita a articulação da PNH com o dispositivo a três pólos da ergologia inspirado 
no conceito de comunidade científica ampliada de Ivar Oddone (Schwartz, $2000 b)$. Este dispositivo procura favorecer articulações entre os três polos: o dos conceitos; o da experiência ou dos saberes gerados nas atividades; e o das exigências éticas e epistemológicas, que se refere ao projeto comum, ao diálogo que se realiza entre os diferentes atores - pesquisadores e trabalhadores.

Nesta discussão sobre o processo de trabalho em que se propõe a ampliação de referenciais marxistas, introduziremos a abordagem ergológica do trabalho como atividade humana e as noções/conceitos associados à mesma.

\section{Debate de normas no uso industrioso de si: a perspectiva ergológica}

Parte-se aqui das elaborações ergológicas de Yves Schwartz sobre o conceito de atividade humana, sempre atravessada pelo 'debate de normas'.

Segundo Schwartz (2000b, 2004a, 2010), a ergologia dialoga, em especial, com as contribuições teóricas de três médicos: 1) o psicólogo e médico Ivar Oddone e o conceito de 'comunidades científicas ampliadas', a partir de experiências com o movimento operário italiano, nas décadas de 1960 e 1970; 2) o filósofo e médico George Canguilhem e a chamada 'filosofia da vida', que, ao tomar o homem como ser da norma, discute as relações entre saúde e doença, entre normal e patológico, a partir da noção de "capacidade normativa", ou seja, "a capacidade de instituir normas diferentes em condições diferentes", referindo-se ao ser vivo doente como aquele que "perdeu a capacidade normativa" (Canguilhem, 2006: 136); 3) o ergonomista e médico Alain Wisner e a 'ergonomia da atividade', ao "reivindicar para as situações a serem estudadas o ponto de vista da atividade" (apud Schwartz, 2004a, p. 37).

Salientamos na abordagem ergonômica o conceito de trabalho prescrito e a noção da distância entre trabalho prescrito e trabalho real, formulado a partir de observações de situações reais de trabalho. Ao analisarem as interfaces ergonomia-ergologia, Telles e Alvarez (2004, p. 63) discutem a noção ergológica de 'norma antecedente' como "possibilidade de ampliação do conceito de trabalho prescrito utilizado na abordagem da ergonomia centrada na análise da atividade".

Conforme nos dizem os ergonomistas:

A distância entre o prescrito e o real é a manifestação concreta da contradição sempre presente no ato de trabalho, entre 'o que é pedido' e 'o que a coisa pede'. A análise ergonômica da atividade é a análise das estratégias (regulação, antecipação, etc.) usadas pelo operador para administrar essa distância, ou seja, a análise do sistema homem/tarefa (Guérin et al., 2001, p. 15). 
Neste diálogo/confronto com a ergonomia, Schwartz (2004a) levantará questões sobre o que diz respeito à atividade de trabalho em oposição à atividade humana em geral. Para os ergonomistas, conforme ressalta Schwartz (2004a, p. 38): “de maneira corrente, a atividade de trabalho é nitidamente distinta da atividade humana em geral", como atividade socialmente finalizada, como uma atividade exigida (ou atividade imposta). Esta abordagem é problematizada pela ergologia a partir da chamada filosofia da vida, de George Canguilhem (2006, 2005, 2001), que, concebendo o homem como ser da norma, entende a vida como atividade de oposição à inércia e à indiferença, o que vai oferecer elementos importantes para a elaboração do conceito ergológico de atividade e da noção de norma antecedente. Importante destacar as reflexões de Canguilhem (2001) sobre o trabalho e o 'governo taylorista' do mesmo, a partir da filosofia da vida e da abordagem do homem como 'ser da norma', capaz de (re)propor, modificando, o meio em que vive e trabalha. Discutindo esta temática, Schwartz nos ajuda a concluir essas breves considerações sobre as relações entre a filosofia da vida, a ergonomia e a ergologia, no que tange à definição de atividade, como oposição à inércia e à indiferença:

Recenseamos as poucas ocorrências breves e luminosas em que sua [de Canguilhem] definição da vida como atividade de oposição à inércia era extrapolada num meio humano de trabalho; em que ela aparecia como o fundamento da resistência operária ao taylorismo e, para além, a toda situação de heterodeterminação das normas industriosas (Schwartz, 2004a, p. 38).

Nesta vertente de discussão sobre a atividade humana em geral e a atividade de trabalho, Schwartz (2004a, p. 39) pergunta: “definir o trabalho pela imposição não é anular em grande parte a inclusão do trabalho na atividade vital concebida como oposição à inércia e à indiferença (...)?”. E o trabalho da dona de casa, do trabalhador informal, do estudante, dentre outros, não seriam considerados trabalho? Nesta perspectiva ergológica aparece uma abordagem do trabalho como uso de si 'por outro' e uso de si 'por si'. Deste ponto de vista, o trabalho não se diferencia da atividade humana em geral. Toda atividade humana, incluindo as diversas formas consideradas como trabalho, é sempre atravessada pelos debates de normas, ou, nas palavras de Schwartz (2004b, p. 25): “a negociação dos usos de si é sempre problemática, sempre lugar de uma dramática. A atividade industriosa é sempre um destino a viver" (grifos do autor).

Abordaremos, a seguir, o conceito de uso de si ('pelos outros' e 'por si mesmo'), as dramáticas do uso de si e o corpo-si, para uma análise da atividade. 


\section{A abordagem ergológica do uso de si no trabalho: as dramáticas e o corpo-si}

O artigo de Yves Schwartz - "Trabalho e uso de si" - , segundo o próprio autor, "foi escrito quando ainda dominava, no campo dos estudos do trabalho, a idéia taylorista do trabalho e a hipótese de encontrar a presença viva de uma pessoa - da subjetividade - na situação de trabalho podia parecer um paradoxo" (Schwartz, 2000a, p. 34).

Procura-se com a introdução da noção de uso de si, enfocando o trabalho como lugar de debates e de gestão (Schwartz, 2004b), estabelecer uma oposição em relação à abordagem taylorista do trabalho como execução. Nas palavras de Schwartz:

(...) quando se diz que o trabalho é uso de si, isto quer dizer que ele é o lugar de um problema, de uma tensão problemática, de um espaço de possíveis sempre a se negociar: há não execução mas uso, e isto supõe um espectro contínuo de modalidades. É o indivíduo no seu ser que é convocado; são, mesmo no inaparente, recursos e capacidades infinitamente mais vastos que os que são explicitados, que a tarefa cotidiana requer, mesmo que este apelo possa ser globalmente esterilizante em relação às virtualidades individuais. (...) Tal é a justificação da palavra "uso" e tal é aqui a forma indiscutível de manifestação de um "sujeito" (Schwartz, 2000a, p. 41).

Nesta perspectiva, entende-se o 'uso' como uso de si 'pelos outros' e uso que "cada um faz de si mesmo, ou seja, o trabalho é sempre também uso de si por si, recentramento do meio de trabalho ao redor de seus possíveis singulares" (Schwartz, 2000a, p. 42).

Mais uma vez, em diálogo com a filosofia da vida de Canguilhem, para a ergologia "este uso de si, nos atos de trabalho como uso de si por si mesmo, traz a marca do que é para o homem a herança da vida nele" (Schwartz, 2000a, p. 44). Articulam-se reflexões sobre normatividade do ser, concepção de saúde como capacidade de renormatização em confrontação com o meio, e uma discussão sobre a questão do 'sujeito' em situação de trabalho, com a introdução das noções de dramáticas do uso de si (ou usos dramáticos de si) e corpo-si.

A 'atividade industriosa', ou seja, aquela que se realiza no mundo do trabalho, mundo produtivo, não difere da atividade humana em geral, sempre um debate de normas, que envolve uma dramática do uso de si, escolhas, posicionamentos. O trabalho definido como atividade humana, em que há sempre 'um destino a viver'. Um drama compreendido como alguma coisa que acontece no trabalho, drama que "não quer dizer necessariamente tragédia (...) é isto, sempre acontece alguma coisa no trabalho" (Schwartz e Durrive, 2007, p. 198). 
A partir desta nova abordagem do trabalho, a ergologia introduz a noção de corpo-si, que, poderíamos dizer, amplia a noção de subjetividade, focada na dimensão do sofrimento no trabalho: "em vez de subjetividade, eu prefiro falar de corpo e de corpo-si" (Schwartz e Durrive, 2007, p. 198, grifos do autor). O corpo não restrito ao sentido biológico, ou a outro qualquer, como oposição à alma, na tradição filosófica, que se constrói a partir de Descartes. E por isso a expressão 'corpo-si', buscando-se construir novo sentido que abarque diferentes dimensões do sujeito, que não se limite a um lugar ou aspecto, mas que envolva tudo que vai do mais biológico ao mais cultural, do ambiente natural da vida ao ambiente cultural, social e psíquico, dentre tantos outros. Este corpo inserido no trabalho, como corpo-si, vai dizer sobre as dramáticas que atravessam a atividade industriosa, quando aquele que trabalha faz escolhas, cria normas, transgride prescrições. Há sempre um debate de normas, processo no qual se confrontam normas antecedentes e o singular da situação de trabalho, em que é necessário criar novas normas, renormatizar; parte daí a noção de 'vazio de normas' da ergologia. E nesse debate, que atravessa toda atividade, a pessoa se implica ${ }^{5}$ inteira, como corpo-si, com seus valores, seu corpo, desejos, paixões, saberes, experiências, história.

O nosso campo de estudos é o trabalho da urgência móvel em saúde, em especial, do Samu do SUS. Discutimos as possibilidades de humanização do trabalho e o agir competente da urgência em saúde do ponto de vista da atividade, compreendida como debate de normas que convoca o sujeito trabalhador como corpo-si na realização de seu trabalho. Buscamos apreender os usos de si e as dramáticas vivenciadas pelos trabalhadores do Samu, cuja lógica hegemônica é a da regulação médica e da aplicação de protocolos. Buscamos identificar no 'infinitamente pequeno' do trabalho da urgência, naqueles atos em que pensamos não haver possibilidade de criação alguma, o que há de debate de normas, de renormatizações ou ressingularizações, de transgressão no curso da atividade.

Como opção metodológica, extraímos das discussões sobre os seis ingredientes da competência, na perspectiva da ergologia (Schwartz, 1998), referenciais com os quais construímos a análise da atividade de trabalho dos profissionais do Samu, no município de Belo Horizonte (BH). Antes de entrarmos na análise propriamente dita, apresentaremos uma síntese dos seis ingredientes.

\section{Os ingredientes da competência do ponto de vista da atividade}

O texto de Schwartz sobre os ingredientes da competência (1998), publicado na França em 1995, aparece no bojo das discussões sobre modelo/avaliação de competências, numa conjuntura de mudanças técnicas organizacionais e econômicas, sendo considerado um marco que organiza o debate da ergologia. 
Poderíamos dizer que o mesmo funda uma perspectiva de análise das competências do ponto de vista da abordagem ergológica, podendo ser tomado como uma boa entrada para a análise da atividade de trabalho nesta perspectiva.

A seguir procura-se elaborar uma síntese de discussões sobre as articulações desses ingredientes no agir em competência, enfatizando-se que esta tentativa de decomposição/ordenação tem como objetivo contribuir para uma maior compreensão dos sentidos atribuídos a cada um deles, possibilitando vislumbrar possibilidades de articulações e interações entre eles.

10 ingrediente: a propriação dos protocolos/saberes protocolares

Refere-se a tudo o que é antecipado, prescrito, o protocolar numa situação de trabalho. Este é o chamado 'polo do Registro l', das normas antecedentes, que abarca os conceitos, a técnica, os saberes considerados científicos ou acadêmicos, dentre outras normas antecedentes, como procedimentos, regras, regulamentos, condições de trabalho.

\section{0 ingrediente: incorporação do histórico/saberes da experiência/ saberes investidos na atividade}

O trabalho segundo a concepção ergológica de atividade humana, como já foi discutido, não se restringe à dimensão conceitual, protocolar; outro polo se articula a esta, o que vai remeter ao segundo ingrediente da competência, ou seja, "a capacidade de se deixar apropriar - quase ser impregnado - pela dimensão singular da situação, pelo histórico, pela dimensão de encontro de encontros" (Schwartz e Durrive, 2007, p. 210).

É o histórico se infiltrando no protocolo, é a singularidade de cada situação de trabalho, são os saberes considerados práticos, ou 'saberes-fazeres', saberes gerados/investidos na atividade, que não se aprendem na escola, que chamaremos aqui de saberes da experiência.

Este segundo ingrediente, considerado 'polo do Registro 2', da experiência, situando-se em oposição ao polo anterior - Registro 1/conceitual -, é adquirido, em parte, na experiência do trabalho, na resolução de problemas - 'competência para preencher furos'. É a dimensão histórica que perpassa os protocolos do trabalho; é a história que atravessa a atividade de trabalho.

\section{0 ingrediente: capacidade para articular 10 e 20 ingredientes}

A abordagem do primeiro e segundo ingredientes nos leva ao terceiro ingrediente do 'agir competente', que é "a capacidade de articular a face protocolar e a face singular de cada situação de trabalho" (Schwartz e Durrive, 2007, p. 212). 
No campo do trabalho em saúde, este terceiro ingrediente vai aparecer de forma exemplar, quando se considera que cada caso é um caso, ou seja, é preciso ajustar sempre o polo conceitual/protocolar à singularidade de cada situação/pessoa a atender. Ressalta-se neste ingrediente a capacidade de articular, dialeticamente, o polo conceitual (Registro 1) e o polo das experiências (Registro 2) no ato de trabalho.

\section{0 ingrediente: o debate de valores que atravessa toda atividade de trabalho}

Na abordagem ergológica da competência, enfatiza-se a questão do trabalho dos valores, que vão orientar escolhas, conscientes ou inconscientes.

Schwartz (1998) aponta para a necessidade de analisar, nas necessárias escolhas e /ou arbitragens evocadas pelas atividades, valores 'dimensionáveis' e valores 'sem dimensão'. Em artigo sobre trabalho e valor, o autor discute para além do valor mercantil do trabalho; ele afirma que, mesmo em atividades reguladas pelo dinheiro (e se poderíamos dizer, atividades mercantis), “os valores que não são de mercado, e entre eles, o 'bem comum', são presentes, operantes, eficazes, mesmo se pouco aparentes" (Schwartz, 1996, p. 153).

Destacando-se, então, a natureza gestionária da atividade, aquele que trabalha debate valores, trazendo questões referentes à eficácia e eficiência dos serviços. Em processos de gestão, o 'polo da eficácia' refere-se à "avaliação de um ato relacionado aos objetivos a que ele visa"; e o "polo da eficência', à "avaliação do produto da atividade referente aos meios disponíveis para produzi-lo" (Schwartz, 2004b, p. 26).

A partir desta perspectiva, Echternacht (2008) discute a temática da gestão da saúde e dos riscos no trabalho, em que busca compreender a gestão de si e da própria saúde como elemento estrutural da atividade humana de trabalho, não dissociada desta enquanto agir competente. Esta abordagem sobre a (auto)gestão da saúde pelo trabalhador - tomando-se este como protagonista nas questões sobre sua saúde no trabalho, e esta como parte do debate de valores que atravessa a atividade - é importante para a análise da atividade de trabalho do Samu, pois este é um tema emergente em rodas de conversas e entrevistas individuais.

Passemos então à abordagem do quinto ingrediente, que vai discutir a relação dos protagonistas da atividade com o saber e a busca de educação permanente.

\section{0 ingrediente: a relação com o saber}

Importante antes de entrarmos na abordagem deste ingrediente, lembrarmos com Schwartz (1998, p. 127), que "há recorrência parcial do ingrediente 4 em todos os outros". 
Ao mesmo tempo, enfatiza-se que a gestão do ingrediente 2 se dá melhor quando se consegue nele inscrever patrimônios, o que significa saberes gerados na atividade que tenham adquirido "valor patrimonial como campo pertinente de sua atividade e de sua vida" (Schwartz, 1998, p. 129).

Introduz-se assim o ingrediente 5, que - como o ingrediente 4 “está fora do alcance das prescrições, das normatizações gerenciais numa situação de trabalho dada. Não se pode prescrever amor ao saber e ao bem comum" (Cunha, 2006, p. 14). Este ingrediente nos diz sobre a relação com o saber, sobre o desejo de buscar aprendizagem e mais qualidade no trabalho, de participar de estudos e oportunidades de educação continuada e/ou permanente.

\section{0 ingrediente: competência para gerir e criar sinergias - as entidades coletivas relativamente pertinentes (ECRP)}

Este ingrediente refere-se à "competência para gerir e criar sinergias entre individualidades e coletivos de trabalho" (Cunha, 2006, p. 14), abordando-se a temática da formação de coletivos em situações reais de trabalho, tanto em função dos objetivos do trabalho, quanto do reconhecimento das possibilidades e limitações de cada um. Esse ingrediente, necessário para assegurar a complementariedade dos demais ingredientes da competência, pode estar disponível em trabalhos coletivos. Ele implica avaliar a si mesmo, suas competências e a dos colegas, a fim de ajustar estratégias coletivas de ação (Cunha, 2006).

As ECRP não correspondem às equipes formais de trabalho, descritas/definidas em organogramas. Nesta perspectiva, o uso de termo 'entidades coletivas', conforme bem expressa Echternacht (2008, p. 61), "referese à invisibilidade de suas fronteiras, na medida em que estas se revelam em coletivos mutantes, com contornos variáveis, independente das configurações sociais predeterminadas". Estas entidades coletivas são 'relativamente pertinentes' porque

se referem a laços que se tecem no viver comum, a partir do compartilhamento de objetivos e valores, em uma permanente construção e reconstrução, condição da imprevisibilidade de sua dinâmica e de suas fronteiras, que são aquelas da atividade humana em um determinado momento (Echternacht, 2008, p. 61).

Em seguida, focaremos uma ocorrência do Samu/BH, quando analisaremos a atividade dos trabalhadores por meio dos ingredientes do agir competente e discutiremos as possibilidades de humanização da atenção e da gestão do Samu/SUS. 


\section{Atividade dos trabalhadores do Samu/BH no atendimento de ocorrência com acidente}

\section{Breve descrição do campo de pesquisa e dos espaços de trabalho}

O Samu, assim denominado nacionalmente, e o número 192, também nacional, para chamadas a este serviço do SUS, foi criado pela portaria n. 1.863/03, que institui a Política Nacional de Atenção às Urgências. Em seguida, tornou-se objeto de uma portaria específica sobre o Samu - a portaria 1.864/03 que "Institui o componente pré-hospitalar móvel da Política Nacional de Atenção às Urgências, por intermédio da implantação de Serviços de Atendimento Móvel de Urgência em municípios e regiões de todo o território brasileiro: Samu 192" (Brasil, 2006a, p. 21). O Samu 192 é objeto também do decreto n. 5.055 da Presidência da República, de 27 de abril de 2004 (Brasil, 2006b).

Resumidamente, o Samu faz parte da rede de serviços do SUS6 e contribui para organizar o atendimento público, ao prestar socorro à população em casos de urgência.

Com este serviço móvel pretende-se reduzir o número de óbitos, o tempo de internação em hospitais e as sequelas decorrentes da falta de socorro precoce. O serviço funciona 24 horas por dia e atende às urgências de natureza traumática, clínica, pediátrica, cirúrgica, gineco-obstétrica e de saúde mental.

O Samu realiza o atendimento de urgência em qualquer lugar: residências, locais de trabalho e vias públicas. O trabalho é organizado pela Central de Regulação Médica, situada em um local específico, denominado 'sede do Samu', que se articula às chamadas 'bases do Samu', situadas em diferentes pontos estratégicos ou regiões do município. Estas bases são pontos de referência para os trabalhadores das ambulâncias, que são utilizadas para o atendimento às diversas ocorrências. A comunicação com a Central de Regulação (resumidamente chamada de 'central' pelos trabalhadores) se realiza por meio de um sistema de radiofones.

Há dois tipos de ambulâncias: 1) Unidade de Suporte Avançado (USA) - considerada como UTI - Unidade de Terapia Intensiva - móvel, contendo instrumentais, equipamentos e tecnologias para prestar assistência como em uma UTI fixa. Conta com um médico, um enfermeiro e o condutor/motorista; 2) Unidade de Suporte Básico (USB) - fazem parte deste tipo de unidade equipamentos e materiais básicos para atendimento ao usuário numa situação de urgência/emergência. Nela trabalham dois técnicos de enfermagem e condutor/motorista.

As bases estão localizadas em pontos estratégicos para deslocamentos em tempo mais curto e constituem espaços de parada e repouso dos trabalhadores. 
Em geral contam com três cômodos (um quarto com dois ou três beliches, copa e banheiro), equipamentos de rádio-comunicação e telefone.

A ligação é atendida por teledigifonistas na Central de Regulação que identificam a urgência e a localização da ocorrência e imediatamente transferem o telefonema para o médico regulador (regulação primária). Esse profissional faz o diagnóstico da situação e inicia o atendimento no mesmo instante, orientando o paciente, ou a pessoa que fez a chamada, sobre as primeiras ações. Além dele, outro profissional contribui para o trabalho na Central, os denominados despachantes, que ficam ao lado dos médicos e fazem o controle das frotas, informando sobre a posição de todos os veículos do Samu por meio de tela específica de computador. Ao mesmo tempo, o médico regulador avalia qual o melhor procedimento para o paciente: orienta a pessoa a procurar um posto de saúde; designa uma ambulância de suporte básico de vida (USB) para o atendimento no local; ou, de acordo com a gravidade do caso, envia uma UTI móvel (USA), com médico e enfermeiro. Com poder de autoridade sanitária, o médico regulador comunica a urgência aos hospitais públicos e, dessa maneira, reserva leitos para que o atendimento de urgência tenha continuidade (regulação secundária).

Em Belo Horizonte, o Samu foi inaugurado em 9 de fevereiro de 2004 e ocupou uma sede provisória e precária até dezembro de 2010, quando foi inaugurada a nova sede, em ponto central da cidade. Neste local, atualmente, situam-se: a Central de Regulação Médica, Transporte Sanitário, Coordenação de Enfermagem, Assistência Social, Gerência do Samu, Núcleo de Estudos e Pesquisas (NEP) e Comissão de Ética, almoxarifado que abastece as ambulâncias, amplo estacionamento, copa, quartos de repouso (masculino e feminino) com beliches, vários banheiros. Vale ressaltar que esta nova sede foi uma conquista dos trabalhadores/gestores e procurou atender às reivindicações referentes à melhoria das condições físicas de trabalho. A Central de Regulação está organizada em amplo espaço, com equipamentos de proteção sonora e ar condicionado, acústica e cadeiras adequadas. Cada turno de trabalho é composto por seis teledigifonistas, cinco médicos reguladores e três despachantes.

Esta breve descrição do campo de pesquisa e dos espaços de trabalho será importante para a análise da atividade a que passaremos a seguir, quando faremos referência a nomes e lugares mencionados neste item.

\section{Crônica da atividade: atendimento a um acidente}

Abordaremos a partir daqui o acompanhamento/observação da atividade dos trabalhadores, vinculados a uma USA, em atendimento a um chamado de urgência (ocorrência, conforme linguagem do Samu) numa situação de acidente com automóveis. 
Usaremos a primeira pessoa do singular, pois se trata de reflexões e análises sobre a experiência de uma das autoras do presente artigo, no acompanhamento de uma ocorrência. Os trechos que compõem a crônica da atividade foram retirados do caderno de campo da pesquisadora. Optamos ainda por manter entre colchetes as reflexões geradas durante a observação, porque as julgamos pertinentes para enfatizar a implicação da mesma na situação de trabalho em foco.

\section{Crônica da atividade do cuidar sem espera}

Na Central de Regulação, converso com um dos médicos presentes sobre possibilidade de acompanhar, como pesquisadora, algum atendimento. Ele mostrou-se preocupado com a questão de segurança e perguntou-me se eu tinha seguro de vida. Informei-lhe que já havia conversado com a gerente sobre isto e mostrei-lhe o comprovante do seguro. Então ele disse que "me levaria" (expressão usada por ele). Logo em seguida surge uma chamada para atender a um acidente. Ele levantou apressado e disse: "Vamos!".

Entramos na USA X. Observo 'o clima' de atenção e disciplina, preparação para chegar ao local. Motorista pede para eu colocar o cinto de segurança. Enfermeira prepara material/instrumentos. [Fico na dúvida se coloco as luvas, decido não usar para marcar minha posição de pesquisadora/observadora, atenta e escutando. Mas se precisasse fazer algo com as mãos? - pesquisadora em atividade - ingredientes 3 e 4 -dramáticas - ao final concluo que teria sido bom usar as luvas. Converso com enfermeira, ela concorda - ajudei a tirar um fio que prendeu na hora de tirar a 'prancha' no hospital; pensei em ajudar a puxar a mesma, mas não o fiz. Uma enfermeira, de outra USA, que estava presente, puxou sozinha, enquanto médico, motorista e enfermeira seguraram o paciente. E eu observando passiva, distante, sem participar? Mas esta é ou não uma pesquisa participante? Muitas questões nesse momento...]. Após esse primeiro dia de vivência em campo, em atividade, decidi colocar as luvas sempre que entrava na ambulância para acompanhar/observar atendimento.

Dentro da ambulância, observo o trabalho da urgência em saúde e o domínio do ingrediente 1 nos primeiros gestos dos trabalhadores, que se manifesta através da apropriação dos protocolos (da urgência em geral e do Samu), regras, técnicas, normas de segurança (seguro de vida, cinto de segurança, luvas, macacão/uniforme etc.), organização dos instrumentos/materiais da ambulância, uso/técnica/manejo dos equipamentos.

Nesse dia o trânsito estava engarrafado - ambulância parada no congestionamento - quase chegando ao local do acidente, quando já se visualizava o movimento em frente, enfermeira e médico decidem sair da ambulância, 
correndo, para chegar mais rápido ao local do acidente, e chegam! Nesta hora, chama atenção a dimensão do trabalho da urgência/emergência: gestos e decisões rápidos, como dizem os trabalhadores: "há risco de vida, salvar vidas". Importante aprofundar esta discussão sobre a dimensão do tempo e da necessidade de agir rápido - salvar a vida de outros enquanto se arrisca a própria vida. Entre regras/protocolos e a necessidade de chegar rápido ao local - uma situação singular - nesta interação dialética entre o ingrediente 1 e o ingrediente 2, opta-se por "pular da ambulância e correr" para chegar rápido e atender às vítimas. Parece que não se pensa, na situação real, em regras/protocolos de segurança (tão importante para este profissional médico), é tudo muito rápido... O que faz com que este trabalhador/sujeito se arrisque tanto para salvar vidas?

Dentro da ambulância, enquanto a enfermeira cuidava da vítima (nesse momento já deitada sobre a prancha/maca, após ter sido retirada do interior do carro e carregada pelos três profissionais envolvidos na atividade - médico, enfermeira e motorista - ECRP - ingrediente 6), o médico me disse: “Gosto deste trabalho, tem emoção! Não gosto de consultório, me dá tédio!".

O tema do risco no trabalho em saúde e, mais especificamente, na urgência/emergência nos remete à discussão sobre a gestão da saúde e dos riscos no trabalho no campo da ergologia (Nouroudine, 2004; Echternacht, 2008), em que a partir do conceito de atividade humana, busca-se compreender a gestão de si e da própria saúde como elemento estrutural da atividade de trabalho. Seguindo com Echternacht (2008, p. 59): “É esta dinâmica valorativa que possibilita a singularização do meio produtivo enquanto tentativa de construção de um meio coerente com as próprias normas de vida". Ressalta-se que tal dinâmica tende ao conflito entre valores mercantis, quantificáveis (que sustentam as normas produtivas, entre elas as normas de gestão da saúde e da segurança no trabalho), e os valores do viver comum, não dimensionáveis: “Tais conflitos de valores possuem frequentemente força suficiente para invibializar a efetivação das normas prescritas pelos gestores da saúde e segurança" (Echternacht, 2008, p. 59).

Neste primeiro dia, junto com os trabalhadores na realização do "trabalho na rua", como pesquisadora em atividade, vivenciei muitas dramáticas, e o corpo-si se implicou inteiro no acompanhamento/observação. Após se expressar sobre o tédio do trabalho em consultório e a emoção do trabalho no Samu, o médico comunicou-se, via radiofone, com a Central de Regulação, quando explicou porque iríamos para o Hospital Pronto Socorro João XXIII e não para o Hospital Municipal Odilon Behrens (HOB). Mais uma vez o congestionamento do trânsito interferia nas decisões do médico, que manifestou sua preocupação com a saúde e vida da paciente e a necessidade de chegar rápido ao hospital. Neste caso o valor não dimensionável - “salvar vidas!" - prevalece nas dramáticas vivenciadas por este trabalhador/médico. 
Terminado o comunicado à Central, quando explicou sua decisão de ir para o João XXIII e não para o HOB (o médico pode decidir isto, tem autoridade, mas deve comunicar à Central, os demais trabalhadores devem seguir conduta indicada pelo médico regulador), o médico olhou para mim e disse: “Tudo é protocolado, se não seguir você se fode!".

Há aqui uma dialética entre ingredientes - 1, 2, 4, 5- produzindo o ingrediente 3: síntese do que se aprendeu nos livros/escola, protocolos da urgência médica e do Samu, dos saberes produzidos no curso da atividade e da experiência, como médico daquele serviço. Para esse profissional, quando há risco de morte (valor não dimensionável), é preciso agir rápido, correr. O tempo aparece como uma categoria importante na realização da atividade de urgência. Segundo definição médica, urgência é "necessidade de agir com rapidez, cuidar sem espera" (Le Petit Robert, citado por GiglioJacquemot, 2005).

Concluímos esta análise, em que se articulam os seis ingredientes do agir competente, com as sábias palavras dos trabalhadores, em diferentes situações de trabalho:

Rotina a gente não tem, cada caso é um caso, tem os protocolos, mas cada caso é um caso... (Técnica de enfermagem, dentro de uma USB, enquanto nos dirigíamos a uma ocorrência).

A gente fica muito feliz, essa é a satisfação da gente, protocolo atendido, faz atendimento conforme protocolo, fez tudo direitinho, pra não aumentar o trauma dele [do usuário], atendimento fino! (Técnica de enfermagem, dentro da ambulância, a caminho de um atendimento).

Insatisfação é quando até pra briga de família chama a gente, chama Samu pra tirar gente dormindo na porta, andarilho... (Técnica de enfermagem, conversas na ambulância).

Através destas palavras, os trabalhadores nos dizem sobre o debate de valores que atravessa a atividade, quando fica evidente a importância que atribuem aos protocolos e ao atendimento que consideram o mais adequado ao Samu. Falam também das articulações entre ingredientes l e 2 e, de alguma forma, demonstram implicação com a regulação/gestão da atividade.

Esse mergulho no curso da ação de ocorrências, buscando captar o ponto de vista da atividade da urgência móvel em saúde, desvelando meandros dramáticos da finalização da Política de Direito à Saúde - razão de ser do SUS - , impõe matérias a pensar: a PNH, como uma política pública que pretende transversalizar/atravessar todas as instâncias e serviços do SUS, desestabilizando fronteiras de saber/poder, abre possibilidades de interferir 
nesses processos de gestão do Samu? Como abrir espaços de análise e debates sobre o trabalho "na rua" (na fala dos trabalhadores) e na Central de Regulação, em que se manifestariam as diferentes regulações e posicionamentos dos trabalhadores? Estes espaços poderiam se constituir a partir dos Colegiados Gestores, das Rodas de Conversas, dos Núcleos de Pesquisa/Estudos em Urgência, dentre outros, como processos democráticos de circulação de palavras, debate de valores e saberes, tomada de decisões diante de questões/dramáticas vivenciadas no trabalho da atenção às urgências? Expandir a Rede Samu pode significar mais do que ampliar/aumentar recursos financeiros para investimentos em Centrais de Regulação e compra de novas ambulâncias? E as condições e a gestão/organização do trabalho, e a valorização do trabalho e dos trabalhadores da saúde, do Samu? Como interferir nesses processos de trabalho? Refletir sobre tais perguntas efetivamente contribuiria para a realização do princípio da indissociabilidade entre atenção e gestão.

\section{Notas}

1 Consultora do Ministério da Saúde, Brasília, Distrito Federal, Brasil. Mestre em Psicologia pela Universidade Federal de Minas Gerais (UFMG) e doutoranda da Faculdade de Educação da UFMG. < aritatrajano@yahoo.com.br>

Correspondência: Ministério da Saúde/Política Nacional de Humanização, Setor de Autarquias Federais Sul, Trecho 02, Bloco F, Edifício Premium, Torre II, sala 102, CEP 70070-600, Brasília, Distrito Federal, Brasil.

2 Professora adjunta do Programa de Pós-Graduação em Educação da Universidade Federal de Minas Gerais (UFMG), Belo Horizonte, Minas Gerais, Brasil. Doutora em Filosofia pela Université de Provence (França). < daisycunha@uol.com.br>

3 A pesquisa é desenvolvida por Ana Rita Castro Trajano, com a orientação de Daisy Moreira da Cunha, que também participa como coautora deste texto.

4 De acordo com Benevides de Barros e Barros de Barros (2007, p. 63): “É com a leitura de Deleuze sobre Foucault (Deleuze, 1991) que vemos destacado o tema das dobras, de tal maneira que as instâncias do dentro e do fora deixam de ser tomadas como faces ou lados opostos das formas-sujeito, instituições, mas como matérias móveis de um plano comum de produção. O esforço teórico-político do(s) autor(es) é o de superar as velhas dicotomias instaladas desde o projeto da modernidade. O saber, o poder e o si são três dimensões irredutíveis, mas em implicação constante".

5 Implicação no sentido atribuído pelos institucionalistas, como engajamento, envolvimento, "compromisso sócio-econômico-político-libidinal" (Baremblitt, 1992).

${ }^{6}$ Mais informações em <http://portal.saude.gov.br/portal/saude>. Acesso em: 5 jan. 2011. 


\section{Referências}

ANTUNES, Ricardo. Adeus ao trabalho? Ensaio sobre as metamorfoses e a centralidade do mundo do trabalho. 4. ed. São Paulo: Cortez; Editora Unicamp, 1997.

BAREMBLITT, Gregório. Compêndio de análise institucional e outras correntes: teoria e prática. Rio de Janeiro: Rosa dos Tempos, 1992.

BENEVIDES de BARROS, Regina; BARROS de BARROS, Maria Elizabeth. Da dor ao prazer no trabalho. In: SANTOS-FILHO, Serafim; BARROS DE BARROS, Maria Elizabeth. (Orgs.). Trabalhador da saúde: muito prazer! Protagonismo dos trabalhadores na gestão do trabalho em saúde. Ijuí: Editora Unijuí, 2007. p. 61-71.

BRASIL. Ministério da Saúde. Política Nacional de Atenção às Urgências. 3. ed. Brasília: Ministério da Saúde, 2006a.

Ministério da Saúde. Regulação médica das urgências. Brasília: Secretaria de Atenção à Saúde/Departamento de Atenção Especializada/Ministério da Saúde, 2006b. (Série A. Normas e Manuais Técnicos).

CAMPOS, Gastão Wagner de Sousa. Um método para análise e co-gestão de coletivos. São Paulo: Hucitec, 2005.

Saúde paidéia. 3. ed. São Paulo: Hucitec, 2007

CANGUILHEM, Georges. Meio e normas do homem no trabalho. Pro-Posições, v. 12, n. 2-3, p. 109-121, 2001.

. Escritos sobre a medicina. Rio de Janeiro: Forense Universitária, 2005.

O normal e o patológico. Rio de Janeiro: Forense Universitária, 2006.

CUNHA, Daisy Moreira. Atividade humana e produção de saberes no trabalho. Trabalho apresentado no $13^{\circ}$ Encontro Nacional de Didática e Prática de Ensino. Recife: Endipe, 2006.

DESLANDES, Suely. Frágeis deuses: profissionais da emergência entre os danos da violência e a recriação da vida. Rio de Janeiro: Editora Fiocruz, 2002.

ECHTERNACHT, Eliza. Atividade humana e gestão da saúde no trabalho: elementos para a reflexão a partir da abordagem ergológica. Laboreal, Porto, v. IV, n. 1, p. 46-55, 2008. Disponível em: <http://laboreal.up.pt>.

FRANCO, Túlio B.; MERHY, Emerson E. Programa de Saúde da Família (PSF): contradições de um programa destinado à mudança do modelo tecnicoassitencial. In: MERHY, E. et al. (Orgs.). O trabalho em saúde: olhando e experienciando o SUS no cotidiano. 3. ed. São Paulo: Hucitec, 2006. p. 55-124.

GIGLIO-JACQUEMOT, Armelle. Urgências e emergências em saúde: perspectiva de profissionais e usuários. Rio de Janeiro: Editora Fiocruz, 2005.

GUÉRIN, François et al. Compreender o trabalho para transformá-lo: a prática da ergonomia. São Paulo: Edgar Blucher, 2001.

HENNINGTON, Élida Azevedo. Contribuições da ergologia para refletir sobre a gestão dos processos de trabalho e a humanização em saúde. In: SIMPÓSIO SOBRE CONDIÇÕES DE SAÚDE E TRABALHO NO SETOR SAÚDE, 1., 2007, Belo Horizonte. Anais... Belo Horizonte: Faculdade de Medicina da UFMG.

HECKERT, Ana; PASSOS, Eduardo; BARROS, Maria Elizabeth Barros de. Um seminário dispositivo: a humanização de Sistema Único de saúde (SUS) em debate. Interface - Comunicação, Saúde, Educação, São Paulo, v. 13, supl. 1, p. 493-502, 2009.

MARX, Karl. O capital. Livro 1 (O processo de produção do capital). São Paulo: Bertrand Brasil; Difel, 1987. v. 1. 
NOUROUDINE, Abdallah. Risco e atividades humanas: acerca da positividade aí presente. In: FIGUEIREDO, Marcelo et al. (Orgs.). Labirintos do trabalho. Rio de Janeiro: DP\&A, 2004. p. 37-62.

PASCHE, Dário Frederico. A saúde coletiva: novo campo de reflexão crítica da saúde. In: PASCHE, Dário; CRUZ, Ivana B. M. da (Orgs.). A saúde coletiva: diálogos contemporâneos. Ijuí: Ed. Unijuí, 2006. p. 21-40. (Coleção Saúde Coletiva).

SANTOS-FILHO, Serafim; BARROS, Maria Elizabeth Barros de (Orgs.). Trabalhador da saúde muito prazer! Protagonismo dos trabalhadores na gestão do trabalho em saúde. Ijuí: Ed. Unijuí, 2007.

SCHWARTZ, Yves. Trabalho e valor. Tempo Social - Revista de sociologia da USP, São Paulo, v. 8, n. 2, p. 147-158, out. 1996.

. Os ingredientes da competência: um exercício necessário para uma questão insolúvel. Educação \& Sociedade, ano XIX, n. 65, p. 101-139, 1998.

. Trabalho e uso de si. Pro-Posições, v. 1, n. 5, p. 34-50, 2000a.

A comunidade científica ampliada e o regime de produção de saberes. Trabalho \& Educação, Belo Horizonte, n. 7, jul./dez. 2000, p. 38-46, 2000 b.

Disciplina epistêmica, disciplina ergológica: paidéia e politéia. Pro-Posições, v. 13, n. 1, p. 126-149, 2002.
Trabalho e saber. Trabalho \& Educação, Belo Horizonte, v. 12, n. 1, p. 21-34, 2003.

Circulações, dramáticas, eficácias da atividade industriosa. Trabalho, Educação e Saúde, Rio de Janeiro, v. 2, n. 1, p. 33$55,2004 a$.

Trabalho e gestão: níveis, critérios, instâncias. In: FIGUEIREDO, Marcelo et al. (Orgs.). Labirintos do trabalho. Rio de Janeiro: DP\&A, 2004b. p. 23-33.

- Conhecer e estudar o trabalho. Texto traduzido por Admardo Júnior e Daisy Cunha. Belo Horizonte: Programa de Pós-Graduação em Educação da Faculdade de Educação da UFMG, 2010. (Mimeo.).

SCHWARTZ, Yves; Durrive, Louis. Trabalho e ergologia: conversas sobre a atividade humana. Tradução de Jussara Brito e Milton Athayde. Rio de Janeiro: EdUFF, 2007.

TAYLOR, Frederick Winslow. Princípios de administração científica. 8. ed. Tradução de Arlindo Vieira Ramos. São Paulo: Atlas, 1990.

TELLES, Ana Luiza; ALVAREZ, Denise. Interfaces ergonomia-ergologia: uma discussão sobre trabalho prescrito e normas antecedentes. In: FIGUEIREDO, Marcelo et al. (Orgs.). Labirintos do trabalho. Rio de Janeiro: DP\&A, 2004. p. 63-90.

TENÓRIO, Gustavo Cunha. A construção da clínica ampliada na Atenção Básica. São Paulo: Hucitec, 2005.

Recebido em 15/02/2011

Aprovado em 22/02/2011 